\title{
Saved by the pump: Two successful resuscitations utilising emergency department-initiated extracorporeal cardiopulmonary resuscitation in South Africa
}

\author{
N Vlok, ${ }^{1}$ MB ChB, Dip RTM (RCSEd), Dip PEC (SA); K A Hedding, ${ }^{1}$ MB ChB, Dip PEC (SA); \\ M A van Dyk, ${ }^{2}$ MB ChB, FCA (SA), Cert Crit Care (SA), PG Dip Clin Ultrasound (Melbourne) \\ ${ }^{1}$ Emergency medical officer, private practice, Pretoria, South Africa \\ ${ }^{2}$ Specialist anaesthesiologist and intensivist, private practice, Pretoria, South Africa
}

Corresponding author: N Vlok (nevillevlok@gmail.com)

Extracorporeal life support is the utilisation of advanced techniques to sustain circulatory and/or ventilatory functions in critically ill patients when standard therapies fail. It is well established in high-income countries. There is increasing literature supporting its application in refractory cardiac arrest with a potential reversible cause, a procedure also known as extracorporeal cardiopulmonary resuscitation (eCPR). Two cases where eCPR was successfully utilised in a busy (>30 000 visits per year) private South African emergency department are described here, the first such cases to be reported on the African continent. The first patient had a life-threatening cardiac arrhythmia due to toxin ingestion, and the second a refractory ventricular fibrillation due to acute myocardial infarction. In both these cases the cardiac arrest was witnessed, occurred in the emergency department, and failed to respond to standard advanced resuscitative measures. Both the patients were discharged neurologically intact. Although it is effective, the benefit of this advanced method of resuscitation in a low- to middle-income country is debated.

S Afr Med J 2021;111(3):208-210. https://doi.org/10.7196/SAMJ.2021.v111i3.15366

In 2021, the three basic pillars of modern cardiac arrest management are still high-quality closed chest compressions, early defibrillation of shockable rhythms, and prompt recognition and treatment of potential reversible causes of cardiac arrest. The reversible causes are commonly known and taught as the 'Hs and Ts', namely hypovolaemia, hypo/ hyperkalaemia, hydrogen-ion/acidosis, hypoxaemia, hypothermia, thrombosis (coronary), thrombosis (pulmonary), tamponade, tension pneumothorax, and lastly toxins. ${ }^{[1,2]}$ Walter Kloeck ${ }^{[3]}$ described a popular, practical 10-step approach using a zig-zag technique during examination to find these reversible causes.

Although the above list serves as a good overview of reversible causes, few interventions can quickly and effectively reverse most of the conditions. For example, coronary thrombosis can be treated with percutaneous coronary intervention (PCI), but in the patient who has a refractory life-threatening arrhythmia, some form of therapy is needed to preserve circulatory function and haemodynamic status while PCI is performed. In the case of hyperkalaemia complicated by cardiac dysrhythmia, emergency dialysis is a very effective therapy, but once again limited by time as a major factor. A life-sustaining 'bridge to therapy' is needed until the underlying cause can be reversed or treated.

Extracorporeal membrane oxygenation (ECMO) is by no means a new therapy, with John Gibbon having used it as early as the 1950s. ${ }^{[4]}$ Since 2009, its use has gained renewed interest, mostly because the H1N1 epidemic has resulted in large numbers of patients with acute respiratory distress syndrome requiring more advanced modes of oxygenation than just mechanical ventilation. ${ }^{[5]}$ Improved technology allowed bedside implementation, resulting in an overall safer, simpler intervention, with fewer complications and avoiding the need for a dedicated ECMO specialist or perfusionist to look after the ECMO circuit. In 2009, a UK-based multicentre randomised controlled trial studying the efficacy and economic assessment of conventional ventilatory support $\mathrm{v}$. extracorporeal membrane oxygenation for severe adult respiratory failure, known as the CESAR trial, provided the first piece of evidence supporting the use of extracorporeal life support (ECLS) in respiratory failure ${ }^{[6]}$ More recently, in 2018, the ECMO to Rescue Lung Injury in Severe ARDS (EOLIA) randomised controlled trial strengthened the evidence supporting the use of ECLS. ${ }^{[7]}$ Subsequent analysis of EOLIA indicated an $11 \%$ absolute mortality reduction with timeous institution of ECMO ${ }^{[8]}$ ECLS is the application of this advanced modality not only in respiratory failure, but also as a mode of cardiovascular or haemodynamic support, although the two terms are at times erroneously used interchangeably ${ }^{[9]}$ Its use is well established in high-income parts of the world such as North America, Europe and Australasia, where increasing literature is being published on its application in refractory cardiac arrest. ${ }^{[10]}$ At the forefront of implementation, extracorporeal cardiopulmonary resuscitation (eCPR) is frequently performed in the prehospital setting in Paris, France, where this highly specialised application has been pioneered with favourable success rates. ${ }^{[11]}$

In South Africa (SA), ECLS is only performed in a handful of specialised centres, with Swanevelder and Firmin's ${ }^{[12]}$ local review article serving as an up-to-date overview of ECLS as a technique in general. Even in these highly specialised centres, the actual number of patients receiving ECLS remains low. The authors postulate that this is mostly due to a variety of factors such as a knowledge gap regarding available therapy, funding difficulty, late referral of suitable patients, paucity of local expertise, and lack of local evidence to support its use. ${ }^{[12]}$ According to our best knowledge, no reports of emergency ECLS implementation in the emergency department (ED) 
for refractory cardiac arrest in SA and Africa have been published to date. We present reports on two patients who successfully received emergency ECLS.

\section{Case reports}

\section{Case 1}

A middle-aged woman was brought to the ED in the late afternoon by the local advanced life support emergency medical service (EMS). She was initially reported as a post-ictal patient, with no apparent threat to life when the EMS arrived. During transport to hospital she suffered a witnessed generalised tonic-clonic convulsion, which was terminated with $4 \mathrm{mg}$ intravenous lorazepam. During EMS handover in the ED, the patient's level of consciousness deteriorated rapidly, without apparent seizure activity, and an advanced airway was placed in order to protect the airway during primary survey. Rapid-sequence intubation using propofol $(1 \mathrm{mg} / \mathrm{kg})$ and rocuronium $(1.2 \mathrm{mg} / \mathrm{kg})$ was uneventful, with successful placement of a size 7.5 endotracheal tube on the first attempt with waveform capnography confirming correct placement.

The patient's first cardiac arrest occurred 5 minutes after intubation, due to a non-perfusing dysrhythmia (polymorphic ventricular tachycardia). Standard advanced life support measures and cardiopulmonary resuscitation (CPR) ensued, with prompt conversion to sinus rhythm after a $200 \mathrm{~J}$ biphasic electrical cardioversion using adhesive pads placed in the anterolateral position. Initial blood chemistry revealed hypokalaemia $(2.3 \mathrm{mmol} / \mathrm{L})$ as well as hyperlactataemia $(18 \mathrm{mmol} / \mathrm{L})$. The patient subsequently suffered loss of cardiac output and again responded to defibrillation and highquality CPR. Further interventions included intravenous lignocaine, potassium correction and magnesium sulphate administration for arrhythmia management. A 12-lead electrocardiogram obtained during a period of return of spontaneous circulation showed no obvious acute myocardial infarction as a cause of arrest.

After the patient's 8th cardiac arrest and limited response to corrected electrolyte abnormalities, the ECMO team was consulted, comprising a cardiothoracic surgeon with significant experience in ECMO cannulation and an ECMO intensivist. They agreed that emergency ECLS was a reasonable intervention. Bedside ultrasound in the form of the rapid ultrasound for shock and hypotension (RUSH) protocol showed no other abnormalities or cause of cardiac arrest. ${ }^{[13]}$ After a total of 12 defibrillations, cannulation was performed using a femoral approach with the venous (drainage) cannula inserted into the right groin and the arterial (return) cannula into the left groin, and ECLS was instituted using the Novalung iLA device (Novalung $\mathrm{GmbH}$, Germany).

The patient was transferred to the intensive care unit, where she remained on both inotropic and ECLS support. Subsequent coronary angiography revealed no coronary atherosclerosis, and ECLS was successfully weaned during the 4 th day. The patient was discharged neurologically intact (cerebral performance category (CPC) 1) after a total stay of 10 days. It was later concluded that she had ingested a large number of caffeine tablets, which accounts for the specific toxidrome of refractory dysrhythmias and profound electrolyte derangements. Although important for explaining the presentation, we consider that this would not have altered therapy if it had been known during resuscitation, as initial therapy was directed towards correcting the abnormalities. Literature regarding application of ECLS in the context of cardiac arrest due to toxin ingestion remains sparse, with single published case reports. In one reported case cardiac arrest was due to ingestion of diphenhydramine (a firstgeneration antihistamine), and in another to severe cardiogenic shock after ingestion of disopyramide (a class 1a anti-arrhythmic agent). ${ }^{[14,15]}$

\section{Case 2}

A man in his 5th decade of life presented via private transport to the ED, complaining of severe chest pain. During triage, he collapsed and was immediately moved to the resuscitation area. He was found to be pulseless due to ventricular fibrillation and was immediately treated with prompt CPR and $200 \mathrm{~J}$ biphasic defibrillation. An advanced airway in the form of a laryngeal mask was placed to ensure adequate oxygenation and to monitor end-tidal carbon dioxide $\left(\mathrm{EtCO}_{2}\right)$ for effectiveness of resuscitation. After delivery of the third defibrillation with no effect, refractory ventricular fibrillation was suspected and the ECMO team was alerted.

During resuscitation, the laryngeal mask was exchanged for a cuffed endotracheal tube while effective manual CPR (evidenced by persistent $\mathrm{EtCO}_{2}$ readings $>20 \mathrm{mmHg}$ ) was underway. The patient also received $300 \mathrm{mg}$ amiodarone intravenously, with no effect. While resuscitation continued, and evaluation and preparation were underway for cannula insertion, an arterial blood gas sample showed severe metabolic acidosis ( $\mathrm{pH}$ 6.8) with no offending electrolyte abnormalities. The patient also received $100 \mathrm{~mL}$ sodium bicarbonate $8.5 \%$.

Cannulation was undertaken using a femoral percutaneous technique, and within 50 minutes after the witnessed arrest the patient was successfully initiated on ECLS, with the cardiac rhythm remaining in ventricular fibrillation. Owing to the history of chest pain and sudden collapse, he was transferred directly to the cardiac catheterisation laboratory for a presumed coronary occlusion. Here it was found that the proximal left anterior descending artery was occluded, and revascularisation with stenting was successfully performed. ECLS was continued for 4 days while the patient's cardiac function gradually recovered. He was discharged after 3 weeks in hospital with excellent cognitive function (CPC 1).

This patient presented with an electrical storm, an almost universally lethal entity. Boehm et al. ${ }^{[16]}$ described the first case of an electrical storm in which dual-axis defibrillation and esmolol administration were successfully used in restoring a perfusing rhythm. It is important to note that dual-axis defibrillation falls outside the current recommendations and esmolol is not widely available in SA, and this method may therefore have limited utility unless better evidence become available. ${ }^{[2]}$

\section{Discussion}

The American Heart Association refers to the 'chain of survival' both for in-hospital and out-of-hospital cardiac arrest in their guidelines for cardiac arrest management. ${ }^{[2]}$ The most important links and steps needed to ensure survival from cardiac arrest are listed in Table 1.

Referring to Table 1, it can be argued that ECLS fits into both the advanced resuscitation and post-cardiac arrest links. In low- to middle-income countries (LMICs), including SA, it would be unwise

Table 1. Chain of survival

\begin{tabular}{|c|c|c|c|c|c|c|}
\hline $\begin{array}{l}\text { IHCA } \\
\mathrm{OHCA}\end{array}$ & $\begin{array}{l}\text { Early recognition and prevention } \\
\text { Prevention }\end{array}$ & $\begin{array}{l}\text { Activation of } \\
\text { emergency response }\end{array}$ & $\begin{array}{l}\text { High-quality } \\
\text { CPR }\end{array}$ & $\begin{array}{l}\text { Advanced } \\
\text { resuscitation }\end{array}$ & $\begin{array}{l}\text { Post-cardiac } \\
\text { arrest care }\end{array}$ & Recovery \\
\hline
\end{tabular}


to actively advocate ECLS as a treatment priority, as numerous barriers, including a lack of basic, context-specific and appropriate strategy to address out-of-hospital cardiac arrest, exist. Some of the current studied barriers and challenges are:

- Poor physical access to emergency hospital care provided by the public sector in sub-Saharan Africa ${ }^{[17]}$

- Lack of basic coronary care, as many South Africans still do not have access to primary PCI for ST-elevated acute myocardial infarction $^{[18]}$

- Suboptimal CPR performance by emergency providers, e.g. Veronese et al.$^{[19]}$ identified that SA intermediate-level emergency medical providers performed poorly during a simulated cardiac arrest study, owing to a major knowledge and skills gap ${ }^{[19]}$

- Lack of local legislation promoting public access to automatic external defibrillators

- Lack of local legislation promoting layperson training and empowerment, with a major opportunity existing to incorporate basic CPR training as part of the national basic education curriculum.

As mentioned in the introductory paragraphs, doctors involved in resuscitation care are often faced with scenarios where a patient shows no response to standard resuscitation measures, or even, in the case of a reversible cause, where definitive therapy addressing the underlying cause is not instantaneously effective, and not appropriate in the resuscitation phase. A temporising measure addressing vital functions such as adequate perfusion and oxygenation would be ideal and therefore perceived to confer some survival benefit. Although it is classically reserved as a component of rescue therapy in critical care, authors such as Mosier et al. ${ }^{[20]}$ describe the initiation of ECLS specifically in the ED both in cardiac arrest and non-cardiac arrest scenarios. eCPR as rescue therapy for out-of-hospital cardiac arrest is growing in popularity in high-income countries, with several case reports and practice recommendations advocating its use. ${ }^{[10,11,21]}$ In situations where the first links in the chain of survival have been adequately addressed and are effective, ECLS as an advanced form of resuscitation would seem to have value in selected instances. The immense challenges with implementing an ECLS programme in LMICs have been described by Elahi et al. ${ }^{[22]}$ Even with the existence and prompt availability of ECLS, selection of patients who will have favourable outcomes with no/minimal disability remains an area of active study. Current practice recommendations ${ }^{[10]}$ indicate that selection should be limited to:

- Patients with a witnessed cardiac arrest with immediate/bystander CPR

- Patients with a high chance of having potentially reversible aetiology

- Situations in which ECLS is achievable within 60 minutes of arrest

- Patients who exhibit any sign of life (spontaneous respiration, pupil response, etc.).

Retrospectively, both patients described in the present case study were correctly selected, as ECLS enabled them to have adequate perfusion and oxygenation in the form of artificial circulation despite ongoing cardiac arrest. Corrective therapy to address the underlying cause was instituted, and ultimately the patients had favourable neurological outcomes despite prolonged cardiac arrest. Although ECPR is not ready for prime time yet in SA owing to financial and systemic constraints, it is exciting to witness a new frontier in advanced resuscitation developing, and we believe that all emergency medicine personnel should be aware of this emerging form of therapy.

\section{Declaration. None.}

Acknowledgements. The authors thank the patients for agreeing to consent for publication. We believe that all identifying features were removed during write-up to maintain patient confidentiality. Proof of consent has been provided to the $S A M J$.

Author contributions. NV: initial and final draft, overall write-up and editing, submission to journal (workload equates to $85 \%$ of total article). KAH: $50 \%$ of case study, patient consent (workload equates to $10 \%$ of total article). MAvD: editing of manuscript (workload equates to $5 \%$ of total article).

Funding. None.

Conflicts of interest. None.

1. Durila M. Reversible causes of cardiac arrest 4 "Ts" and 4 "Hs" can be easily diagnosed and remembered following general ABC rule, Motol University Hospital approach. Resuscitation 2018;126:e7. https://doi.org/10.1016/..resuscitation.2018.03.013

2. Merchant RM, Topjian AA, Panchal AR, et al.; Adult Basic and Advanced Life Support, Pediatric Merchant RM, Topjian AA, Panchal AR, et al.; Adult Basic and Advanced Life Support, Pediatric
Basic and Advanced Life Support, Neonatal Life Support, Resuscitation Education Science, and Systems of Care Writing Groups. Part 1: Executive summary: 2020 American Heart Association Guidelines for Cardiopulmonary Resuscitation and Emergency Cardiovascular Care. Circulation 2020;142(16_Suppl_2):S337-S357. https://doi.org/10.1161/CIR.0000000000000918

3. Kloeck WG. A practical approach to the aetiology of pulseless electrical activity: A simple 10-step training mnemonic. Resuscitation 1995;30(2):157-159. https://doi.org/10.1016/03009572(95) $99840-7$

4. Dodd DT. The Gibbon heart-lung machine: Origin, national and local status. Am Surg 1958;24(8):539-546.

5. Viasus D, Oteo Revuelta JA, Martínez-Montauti J, Carratalà J. Influenza A(H1N1)pdm09-related pneumonia and other complications. Enferm Infecc Microbiol Clin 2012;30(Suppl 4):43-48. https:// pneumonia and other complications. Enfer
doi.org/10.1016/S0213-005X(12)70104-0

6. Peek GJ, Mugford M, Tiruvoipati R, et al. Efficacy and economic assessment of conventional 6. Peek GJ, Mugford M, Tiruvoipati R, et al. Efficacy and economic assessment of conventional
ventilatory support versus extracorporeal membrane oxygenation for severe adult respiratory failure (CESAR): A multicentre randomised controlled trial. Lancet 2009;374(9698):1351-1363. https://doi org/1016/\$0140-6736(09)61069-2

7. Combes A, Hajage D, Capellier G, et al.; EOLIA Trial Group, REVA, and ECMONet. Extracorporeal membrane oxygenation for severe acute respiratory distress syndrome. N Engl J Med 2018;378(21):1965-1975. https://doi.org/10.1056/NEJMoa1800385

8. Gattinoni L, Vasques F, Quintel M. Use of ECMO in ARDS: Does the EOLIA trial really help? Crit Care 2018;22:171. https://doi.org/10.1186/s13054-018-2098-6

9. McRae K, de Perrot M. Principles and indications of extracorporeal life support in general thoracic surgery. J Thorac Dis 2018;10(Supp1 8):S931-S946. https://doi.org/10.21037/jtd.2018.03.116

10. Hutin A, Abu-Habsa M, Burns B, Bernard S, Bellezzo J, Shinar Z. Early ECPR for out-of-hospital cardiac arrest: Best practice in 2018. Resuscitation 2018;130:44-48. https://doi.org/10.1016/j. cardiac arrest: Best practice
resuscitation.2018.05.004

11. Lamhaut L, Hutin A, Puymirat E, Jouan J, Raphalen JH, Jouffroy R. A pre-hospital extracorporeal camhaut $\mathrm{L}$, Hutin $\mathrm{A}$, Puymirat $\mathrm{E}$, Jouan J, Raphalen $J \mathrm{H}$, Jouffroy R. A pre-hospital extracorporea
cardio pulmonary resuscitation (ECPR) strategy for treatment of refractory out hospital cardiac arrest: An observational study and propensity analysis. Resuscitation 2017;117:109-117. https://do org/10.1016/j.resuscitation.2017.04.014

12. Swanevelder JLC, Firmin RK. Extracorporeal circulatory/life support: An update. J Card Crit Care 2017;1(2):65-71. https://doi.org/10.1055/s-0038-1626674

13. Keikha M, Salehi-Marzijarani M, Soldoozi Nejat R, Sheikh Motahar Vahedi H, Mirrezaie SM Diagnostic accuracy of rapid ultrasound in shock (RUSH) exam: A systematic review and metaanalysis. Bull Emerg Trauma 2018;6(4):271-278. https://doi.org/10.29252/beat-060402

14. Labarinas S, Meulmester K, Greene S, Thomas J, Virk M, Erkonen G. Extracorporeal cardiopulmonary resuscitation after diphenhydramine ingestion. J Med Toxicol 2018;14(3):253-256. https://doi.org/10.1007/s13181-018-0672-6

15. Iguchi $\mathrm{S}$, Yamaguchi $\mathrm{N}$, Takami $\mathrm{H}$, et al. Higher efficacy of direct hemoperfusion using coated Iguchi $\mathrm{S}$, Yamaguchi $\mathrm{N}$, Takami $\mathrm{H}$, et al. Higher efficacy of direct hemoperfusion using coated
activated-charcoal column for disopyramide poisoning: A case report. Medicine (Baltimore) activated-charcoal column for disopyramide poisoning: A case

16. Boehm KM, Keyes DC, Mader LE, Moccia JM. First report of survival in refractory ventricular fibrillation after dual-axis defibrillation and esmolol administration. West J Emerg Med 2016;17(6):762-765. https://doi.org/10.5811/westjem.2016.8.30351

17. Ouma PO, Maina J, Thuranira PN, et al. Access to emergency hospital care provided by the public sector in sub-Saharan Africa in 2015: A geocoded inventory and spatial analysis. Lancet Glob Health 2018:6(3):e342-e350. https://doi.org/10.1016/S2214-109X(17)30488-6

18. Stassen W, Wallis L, Lambert C, Castren M, Kurland L. Percutaneous coronary intervention still no accessible for many South Africans. Afr J Emerg Med 2017;7(3):105-107. https://doi.org/10.1016/j. afjem.2017.04.009

19. Veronese JP, Wallis L, Allgaier R, Botha R. Cardiopulmonary resuscitation by emergency medical services in South Africa: Barriers to achieving high quality performance. Afr J Emerg Med 2018;8(1):6-11. https://doi.org/10.1016/j.afjem.2017.08.005

20. Mosier JM, Kelsey M, Raz Y, et al. Extracorporeal membrane oxygenation (ECMO) for critically ill Mosier JM, Kelsey M, Raz Y, et al. Extracorporeal membrane oxygenation (ECMO) for critically ill
adults in the emergency department: History, current applications, and future directions. Crit Care adults in the emergency department: History, current app
2015;19:431. https://doi.org/10.1186/s13054-015-1155-7

21. Bellezzo JM, Shinar Z, Davis DP, et al. Emergency physician-initiated extracorporeal cardiopulmonary resuscitation. Resuscitation 2012;83(8):966-970. https://doi.org/10.1016/j. resuscitation.2012.01.027

22. Elahi MM, Shahzad A, Khan AM, et al. Initiating an adult and paediatric extracorporeal membrane oxygenation (ECMO) program in a developing country: Challenges, successes, opportunities and road ahead. J Cardiol Curr Res 2016;7(2):00245. https://doi.org/10.15406/jccr.2016.07.00245 